\title{
Lidamycin shows highly potent cytotoxic to myeloma cells and inhibits tumor growth in mice
}

\author{
Yong-zhan ZHEN ${ }^{1,2}$, Ya-jun LIN ${ }^{1}$, Yi LI ${ }^{1}$, Yong-su ZHEN ${ }^{1, *}$ \\ ${ }^{1}$ Institute of Medicinal Biotechnology, Chinese Academy of Medical Sciences \& Peking Union Medical College; Beijing 100050, China; \\ ${ }^{2}$ North China Coal Medical College, Tangshan 063000, China
}

\begin{abstract}
Aim: To investigate the effects of lidamycin (LDM) on a mouse myeloma cell line (SP2/0) and human multiple myeloma cell lines (U266 and SKO-007), and provide the basis for the use of LDM in cancer therapy.

Methods: A 3-[4,5-dimethylthiazol-2-yl]5-[3-carboxymethoxyphenyl]-2-[4-sulfophenyl]2H-tetrazolium inner salt (MTS) assay was used to determine the degree of growth inhibition by the drugs analyzed in this study. Cell cycle distribution and analysis were measured by flow cytometry combined with propidium iodide (PI) staining. The effects on apoptosis were measured by Hoechst 33342 staining and by flow cytometry combined with fluorescein-isothiocyanate-Annexin V/propidium iodide (FITC-Annexin V/PI) staining. Protein expression was determined by Western blot analysis. In vivo antitumor activity was measured using a murine myeloma model in BALB/C mice.

Results: There was a significant reduction in cell proliferation after treatment with LDM. The overall growth inhibition correlated with increased apoptotic cell death. LDM-induced cell apoptosis was associated with the activation of c-Jun-N-terminal kinase (JNK), and cleavage of caspase-3/7 and poly (ADP-ribose) polymerase (PARP). LDM markedly suppressed tumor growth in a murine myeloma model.

Conclusion: LDM induces apoptosis in murine myeloma SP2/0 cells as well as in human myeloma U266 and SKO-007 cell lines. The sustained activation of JNK might play a critical role in LDM-induced apoptosis in the SP2/0 cell line. LDM demonstrates significant antitumor efficacy against myeloma SP2/0 cells in mice. Taken together, our data provide some clues for further research of the effects of LDM on human multiple myeloma.
\end{abstract}

Keywords: lidamycin; mouse myeloma; multiple myeloma; JNK; SP2/0 cells

Acta Pharmacologica Sinica (2009) 30: 1025-1032; doi: 10.1038/aps.2009.75

\section{Introduction}

Multiple myeloma (MM) is a type of cancer of plasma cells, which are immune-system cells in the bone marrow that produce antibodies. Little progress in the treatment of this disease has been made despite decades of treatment with various chemotherapy regimens, which have resulted in 5-year survival rates of $<10 \%{ }^{[1]}$. Although high-dose chemotherapy and stem cell transplantation have improved the rate of complete remission, some myeloma cells escape from treatment and thus almost all MM patients experience relapse ${ }^{[2]}$. New agents are expected to offer long-term disease control, or possibly even a cure. Two new drug classes have radically changed the management of multiple myeloma. Thalidomide analogues ${ }^{[3]}$ and bortezomib ${ }^{[4,5]}$ are in the process of replacing the current treatment paradigm of anthracycline, vinca alkaloid and

* To whom correspondence should be addressed.

E-mail zhenys@public.bta.net.cn

Received 2008-12-29 Accepted 2009-04-24 dexamethasone-based chemotherapy followed by autologous bone marrow transplantation.

Plasma cell myeloma occurs spontaneously, but rarely, in $\mathrm{C} 3 \mathrm{H}, \mathrm{AK}, \mathrm{BALB} / \mathrm{c}^{[6]}$, and several other strains of mice. The SP2/0 mouse myeloma cell line is usually used as a partner for making mouse hybridoma-producing monoclonal antibodies $^{[7]}$.

Lidamycin (LDM, originally named C-1027) is a member of the enediyne antibiotic family, which was derived from a Streptomyces globisporus C1027 strain $^{[8]}$. As a DNA damaging agent, LDM is characterized by inducing a higher ratio of DNA double-strand breaks (DSBs) than single-strand breaks $(\mathrm{SSBs})^{[9]}$. It is well known that DSB is the most severe DNA lesion, which may explain the highly potent cytotoxicity of LDM toward cancer cells. LDM shows extremely potent cytotoxicity, anti-angiogenic activity and a marked inhibition of transplantable tumors in mice ${ }^{[9-11]}$. The LDM molecule contains an enediyne chromophore $\left(M_{\mathrm{r}} 843 \mathrm{Da}\right)$ responsible for the extremely potent bioactivity and a noncovalently bound 
apoprotein $\left(M_{\mathrm{r}} 10.5 \mathrm{kDa}\right)$, which forms a hydrophobic pocket for protecting the chromophore ${ }^{[12]}$. The apoprotein and chromophore can be dissociated and reconstituted, and the biological activity of the rebuilt molecule is comparable to that of the natural LDM ${ }^{[13]}$.

LDM can induce apoptosis or mitotic cell death in many cancer cells ${ }^{[14,15]}$. Recent studies have indicated that LDM induces unusual DNA damage responses to double-strand breaks ${ }^{[16]}$. It alters cell cycle progression and induces chromosomal aberrations ${ }^{[17,18]}$. As reported, the antitumor effect of LDM could be amplified by other agents ${ }^{[19]}$.

LDM is presently undergoing phase II clinical trials in China. The vast majority of studies aimed at elucidating the mode of action of LDM have been performed in solid cancer cells. So far, there are no reports describing the effects of LDM on myeloma cells. In the present study, we investigated the mechanisms of LDM-induced cytotoxicity in the mouse myeloma SP2/ 0 cell line as well as in human myeloma cell lines, including U266 and SKO-007. We observed that LDM induced apoptosis in a dose-dependent manner. LDMinduced apoptosis was associated with increasing c-Jun NH2terminal kinase (JNK) and cleavage of caspase-3/7 and poly (ADP-ribose) polymerase (PARP). Inhibition of JNK activity reduced LDM-induced cytotoxicity and apoptosis, suggesting that JNK played important roles in LDM-induced cytotoxicity and apoptosis. Moreover, LDM induced $\mathrm{G}_{2} / \mathrm{M}$ phase arrest in SP2/0, U266, and SKO-007 cell lines and suppressed the growth of tumors in BALB/c mice. These data provide some clues for further study of the effects of LDM on human multiple myeloma.

\section{Materials and methods}

\section{Cell culture and chemicals}

Mouse myeloma SP2/0 cells were cultured in DMEM (Gibco BRL, Grand Island, NY) and human MM cell lines U266 and SKO-007 were cultured in RPMI-1640 (Gibco BRL, Grand Island, NY) supplemented with $10 \%$ heat-inactivated fetal bovine serum (Sigma Chemical Co, St Louis, Missouri), 100 $\mathrm{U} / \mathrm{mL}$ penicillin, and $100 \mu \mathrm{g} / \mathrm{mL}$ streptomycin at $37^{\circ} \mathrm{C}$ in a humidified atmosphere containing $5 \% \mathrm{CO}_{2}$. SP2/0, U266 and SKO-007 cell lines were kindly provided by Prof Bei-fen SHEN (Beijing Institute of Basic Medical Sciences).

LDM was generously provided by Prof Lian-fang JIN (Institute of Medicinal Biotechnology, CAMS). LDM stock solution $(10 \mu \mathrm{mol} / \mathrm{L})$ was prepared in $0.9 \% \mathrm{NaCl}$ and stored at $-70{ }^{\circ} \mathrm{C}$. 5-Fluorouracil (5-FU) was the product of Shanghaixudong Pharmaceutical Co, Ltd, China. Dexamethasone (DEX) was obtained from Jiangsusuxin Pharmaceutical Co, Ltd, China. Adriamycin (ADM), and vincristine (VCR) were purchased from Shenzhenwanle Pharmaceutical Co, Ltd, China. All other chemicals were of standard analytical grade.

\section{Western blotting}

Cells were harvested, and washed with PBS solution. Whole cell extracts were prepared by incubating cells on ice in lysis buffer containing $50 \mathrm{mmol} / \mathrm{L}$ Tris- $\mathrm{HCl}, \mathrm{pH} 7.5,150 \mathrm{mmol} / \mathrm{L}$ $\mathrm{NaCl}, 2 \mathrm{mmol} / \mathrm{L}$ EDTA, $2 \mathrm{mmol} / \mathrm{L}$ EGTA, $1 \mathrm{mmol} / \mathrm{L}$ dithiothreitol, $1 \%$ Nonidet P-40, $0.1 \%$ SDS, protease inhibitors (1 $\mathrm{mmol} / \mathrm{L}$ PMSF, $5 \mu \mathrm{g} / \mathrm{mL}$ aprotinin, $5 \mu \mathrm{g} / \mathrm{mL}$ leupeptin and $5 \mu \mathrm{g} / \mathrm{mL}$ pepstatin) and phosphatase inhibitors $(20 \mathrm{mmol} / \mathrm{L}$ [beta]-glycerophosphate, $50 \mathrm{mmol} / \mathrm{L} \mathrm{NaF}$ and $1 \mathrm{mmol} / \mathrm{L}$ $\mathrm{Na}_{3} \mathrm{VO}_{4}$. The cell lysates were cleared by centrifugation at $12000 \times \mathrm{g}$ for $12 \mathrm{~min}$. Protein concentrations were determined by the Bradford assay. Equal amounts of lysate $(40 \mu \mathrm{g})$ were resolved by SDS-PAGE and transferred to polyvinylidene difluoride membrane (Millipore Corp, Bedford, MA). Membranes were blocked in TBST containing 5\% nonfat skim milk at room temperature for $2 \mathrm{~h}$ and probed with primary antibodies overnight at $4{ }^{\circ} \mathrm{C}$. Then membranes were blotted with an appropriate horseradish peroxidase-linked secondary antibody (Santa Cruz Biotechnology). Proteins were visualized using enhanced chemiluminescence Western blotting detection reagents (Amersham Pharmacia Biotech, Inc, Piscataway, NJ, USA).

\section{Cell proliferation assay}

Cell proliferation was determined using CellTiter $96^{\circledR}$ Aqueous Non-Radioactive Cell Proliferation Assay (Promega, Madison, WI, USA) according to the manufacturer's protocol. Briefly, cells $(10000$ cells/well) were plated in triplicate in 96-well flat-bottom plates in $90 \mu \mathrm{L}$ of culture medium without any anticancer drug. After $2 \mathrm{~h}$ incubation, triplicate wells were treated with anticancer drugs $(10 \mu \mathrm{L})$ at various concentrations. Cells were exposed to $20 \mu \mathrm{L}$ of the solution containing MTS and PMS (MTS and PMS at the ratio of 20:1) for the last 4 $\mathrm{h}$ of 48 -h cultures. The absorbance was read at $490 \mathrm{~nm}$ using a Microplate Reader (Thermo Labsystem, USA). The experiments were done at least three times, with each experiment consisting of samples in triplicate.

\section{Cell cycle analysis}

Cells were collected and fixed in ice-cold 70\% ethanol and stored at $4{ }^{\circ} \mathrm{C}$ overnight. Samples were then washed twice in PBS and re-suspended in a solution of PI $(50 \mu \mathrm{g} / \mathrm{mL})$ and RNase A $(200 \mu \mathrm{g} / \mathrm{mL})$ in PBS for $30 \mathrm{~min}$ at $37^{\circ} \mathrm{C}$ in the dark. The stained cells were filtered through $40 \mu \mathrm{m}$ gauzes, and the single-cell suspensions were analyzed on a Fluorescenceactivated cell sorter (EPICS, Coulter).

\section{FITC-Annexin V/PI apoptosis assay}

Cells were collected and resuspended in $200 \mu \mathrm{L}$ binding buffer. Then $10 \mu \mathrm{L}$ FITC-labeled Annexin V and $100 \mathrm{ng}$ propidium iodide were added. Upon incubation in the dark (15 min, at room temperature or $30 \mathrm{~min}$ at $4{ }^{\circ} \mathrm{C}$ ), the samples were diluted with $300 \mu \mathrm{L}$ binding buffer. Flow cytometry was carried out on a FACScan instrument (Becton Dickinson) and data were processed with WinMDI/PC-software.

\section{Staining with Hoechst 33342}

SP2/0 cells were treated with control media or LDM at various concentrations for $48 \mathrm{~h}$, and then the cells were collected. 
After being centrifuged and washed with PBS, cells were fixed with $4 \%$ paraformaldehyde for $10 \mathrm{~min}$ at room temperature and then washed with PBS. Hoechst $33342(5 \mu \mathrm{g} / \mathrm{mL})$ was added to the fixed cells, and they were incubated for $10 \mathrm{~min}$ at room temperature. Then cells were spread on coverslips and imaged using an Olympus IX-70 inverted fluorescent microscope.

\section{In vivo therapeutic effects}

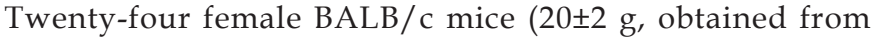
the Institute for Experimental Animals, Chinese Academy of Medical Sciences, Beijing) at the age of 4-6 weeks, were used for SP2/0 mouse myeloma isografts. Animals were randomly divided into groups $(n=6)$ in a manner that minimized the difference in body weight between the groups. SP2/0 cells $\left(1 \times 10^{6}\right)$ resuspended in $200 \mu \mathrm{L}$ PBS were injected subcutaneously into BALB/c mice. On day +1 after inoculation, mice were receiving LDM or PBS (vehicle control) treatment. Treatment with LDM or PBS (vehicle control) was given intravenously once weekly via tail vein for a total of two injections. The doses of LDM were $0.06,0.04$, and $0.02 \mathrm{mg} / \mathrm{kg}$, respectively. Mice were weighed and tumor sizes were measured with a caliper and recorded every 3 days. The tumor volume was determined using the formula $\left(\right.$ length $\times$ width $\left.^{2}\right) \times 0.5$.

\section{Statistics analysis}

Results are indicated as the means $\pm S D$. Treatment effects were compared using the Student's $t$ test and differences between the means were considered to be significant when $P<0.05$.

\section{Results}

\section{Cytotoxicity of LDM to SP2/0 cells}

We examined the growth inhibitory effect of LDM in the SP2/0 cell line using the MTS assay as described in Materials and methods. Cells were cultured for $48 \mathrm{~h}$ (Figure 1A) in the presence of LDM at various concentrations. Meanwhile, several conventional therapeutic agents, including ADM, 5-FU, VCR, and DEX, were also used in the assay. SP2/0 cells showed decreased cell proliferation after treatment with the drugs, especially the cells exposed to LDM. The $\mathrm{IC}_{50}$ value of LDM for the SP2/ 0 was $0.5623 \pm 0.0051 \mathrm{nmol} / \mathrm{L}$, lower than those of the other drugs (ADM, 5-FU, VCR, and DEX were $177.8 \pm 19.7 \mathrm{nmol} / \mathrm{L}, 178.0 \pm 22.5 \mathrm{nmol} / \mathrm{L}, 275.0 \pm 18.9 \mathrm{nmol} / \mathrm{L}$, and $155000 \pm 360 \mathrm{nmol} / \mathrm{L}$, respectively). In terms of $\mathrm{IC}_{50}$ values, the cytotoxicity of LDM was much more potent than that of the other tested drugs. Cells were cultured with LDM (0.01, $0.1,0.5$, and $1 \mathrm{nmol} / \mathrm{L}$ ) for the indicated times and also analyzed with the MTS assay (Figure 1B). SP2/0 cells treated with the indicated dose of LDM showed decreased cell proliferation in a time-dependent manner. Similar results were observed in U266 and SKO-007 cell lines (data not shown).

Induction of apoptosis by LDM in SP2/0, U266, and SKO-007 cells

We next investigated the molecular mechanisms whereby
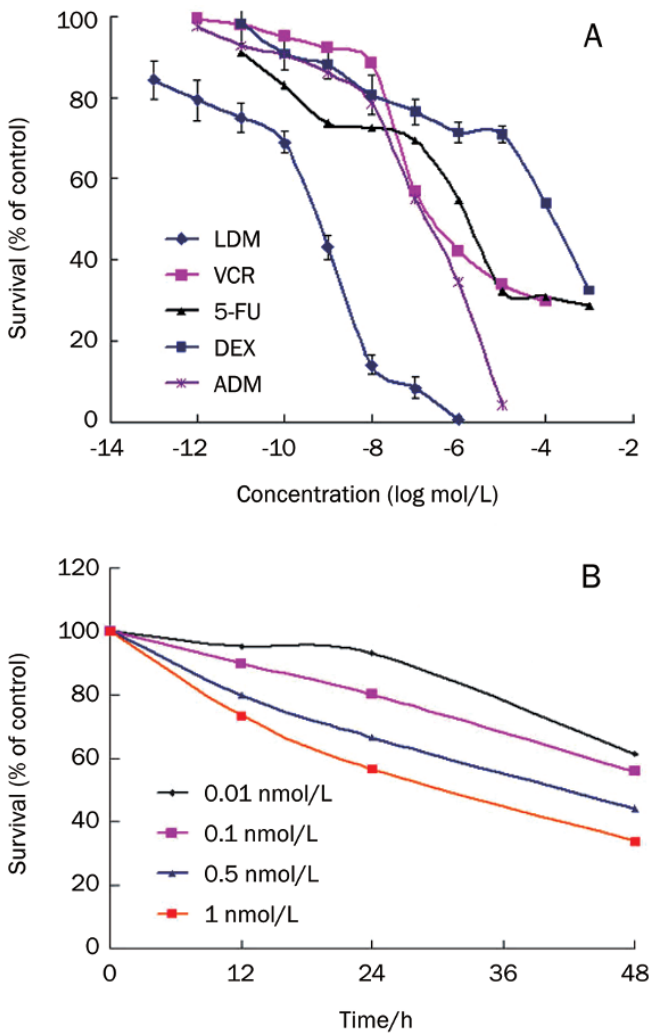

Figure 1. Growth inhibition of SP2/0 cells by LDM and other drugs. (A) Cells were exposed to the drugs for $48 \mathrm{~h}$ and determined by MTS. (B) Cells were cultured with $\operatorname{LDM}(0.01,0.1,0.5$, and $1 \mathrm{nmol} / \mathrm{L})$ for the indicated time and determined by MTS. Data are from three independent experiments. VCR, vincristine; 5-FU, 5-fluorouracil; DEX, dexamethasone; ADM, adriamycin.

LDM induces cytotoxicity in SP2/0, U266, and SKO-007 cells. We first performed cell-cycle profiling using PI staining, Hoechst 33342 staining and FITC-Annexin V/PI staining in the three cell lines. Cells were cultured for $48 \mathrm{~h}$ with control media or $\operatorname{LDM}(0.1,0.5,1$, and $2 \mathrm{nmol} / \mathrm{L})$. PI staining showed that LDM induced cell cycle arrest at the $\mathrm{G}_{2} / \mathrm{M}$ phase in SP2/0 cells. At $0.5 \mathrm{nmol} / \mathrm{L} \mathrm{LDM}$, the number of $\mathrm{G}_{2} / \mathrm{M}$ phase cells reached the peak. Similar results were observed in U266 and SKO-007 cell lines (Figure 2).

By Hoechst 33342 staining, the nuclei of untreated cells were normal in appearance and exhibited diffuse staining of chromatin. After exposure to LDM for $48 \mathrm{~h}$, most cells presented the typical morphological changes associated with apoptosis, such as chromatin condensation or a shrunken nucleus (Figure 3).

FITC-Annexin V/PI staining showed that LDM at 0.1 $\mathrm{nmol} / \mathrm{L}$ induced earlier apoptosis in SP2/0 cells. The ratio of apoptotic to living cells was significantly enhanced when cells were incubated with 1 or $2 \mathrm{nmol} / \mathrm{L} \mathrm{LDM} \mathrm{for} 48 \mathrm{~h}$. This suggests that apoptosis was the predominant mode of LDM-induced cell death (Figure 4). Similar results were observed in U266 and SKO-007 cell lines (data not shown). 
SP2/0
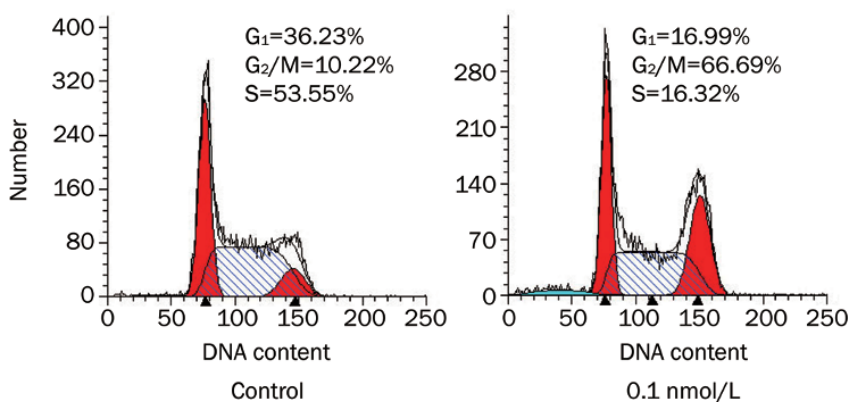

U266
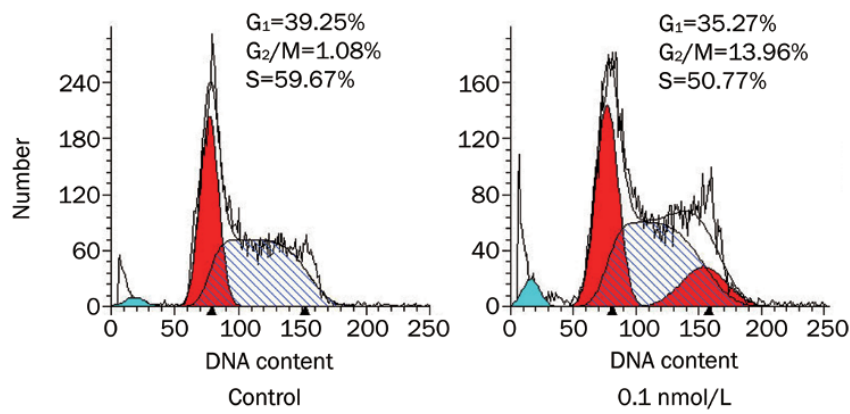

SKO-007
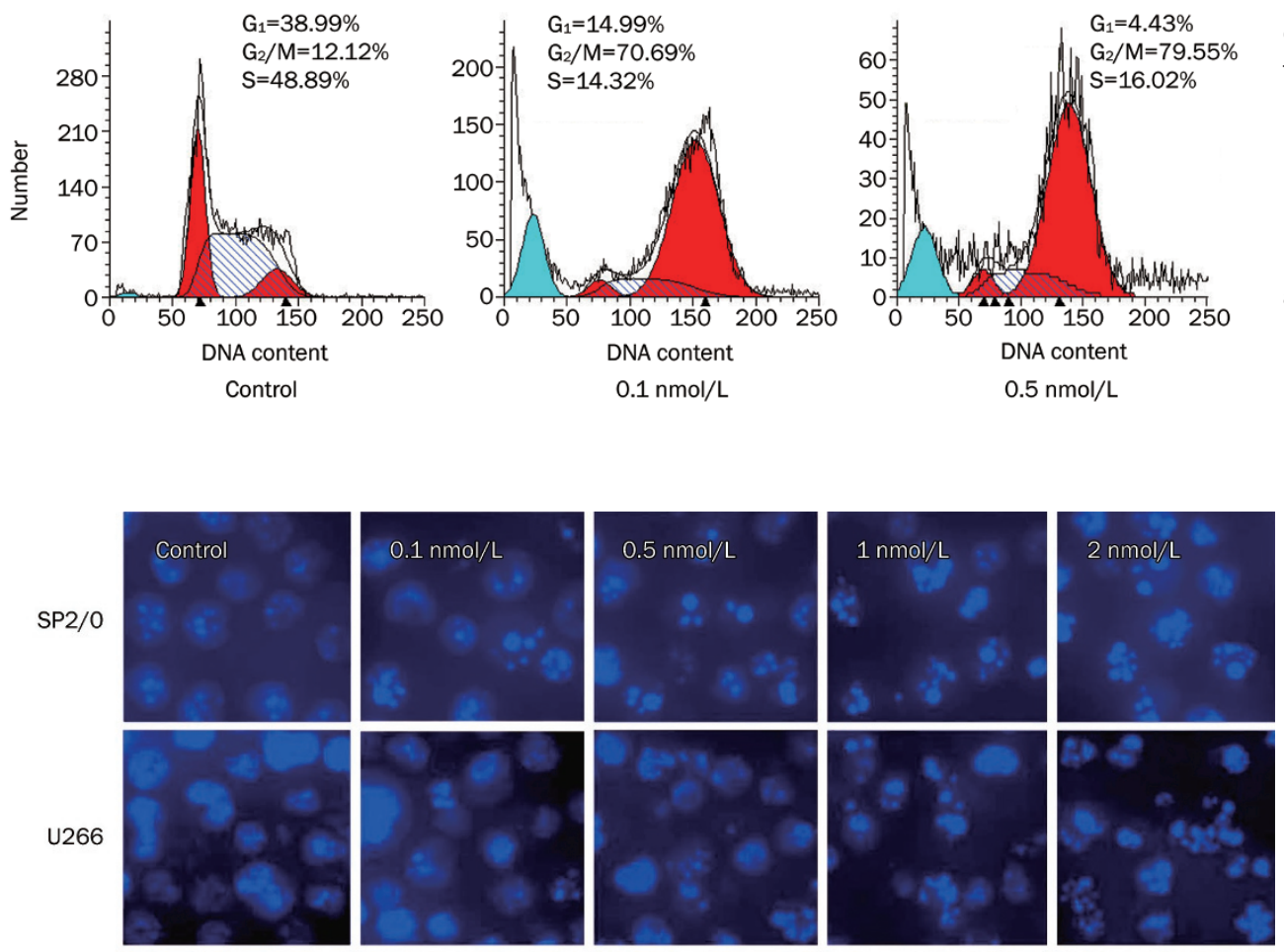

SKO-007
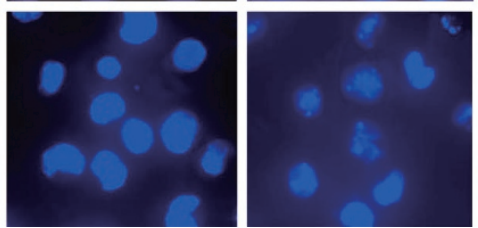

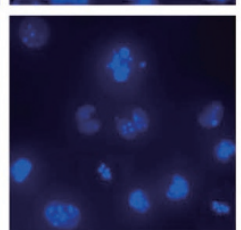

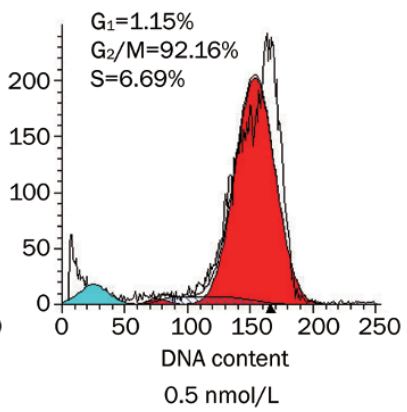

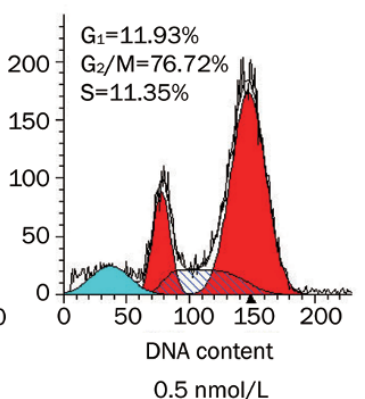

Figure 2. Cell cycle analysis of cells treated with LDM. Cells were stained with $\mathrm{Pl}$ after a $48 \mathrm{~h}$ exposure to different concentrations of LDM. Percentages of the total cell population in the different phases of the cell cycle were determined by flow cytometric analysis. The $G_{2} / M$ ratios of control, $0.1 \mathrm{nmol} / \mathrm{L}$ LDM and 0.5 nmol/L LDM are 10.22\%, 66.69\%, and $76.72 \%$ in SP2/0 cells; $1.08 \%, 13.96 \%$, and $92.16 \%$ in U266 cells; $12.12 \%$, $70.69 \%$, and $79.55 \%$ in SKO-007 cells, respectively.

Figure 3. Induction of cell apoptosis by LDM in SP2/0, U266, and SKO-007 cells. Cells were treated with LDM for $48 \mathrm{~h}$ at the indicated concentrations and then stained with DNA-binding dye, Hoechest $33342(\times 400)$. One representative of three independent experiments is shown. 

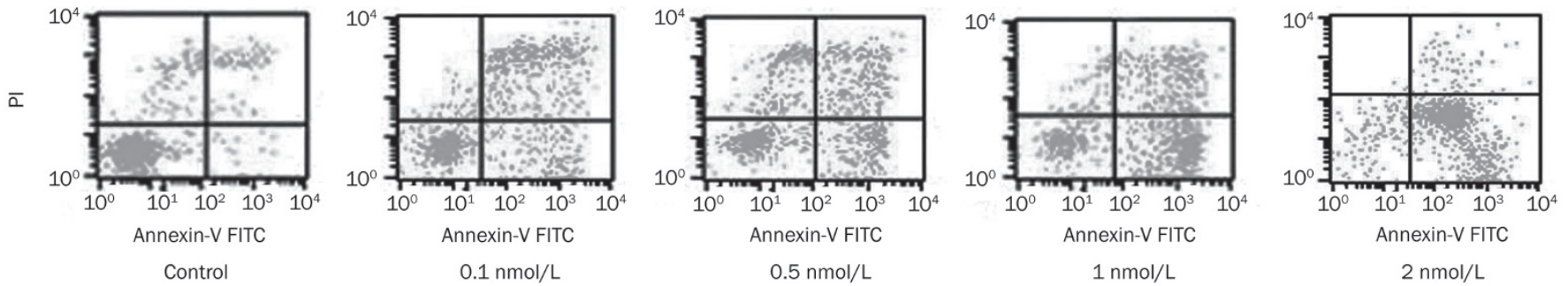

Figure 4. Induction of cell apoptosis by LDM in SP2/0 cells. Cells were treated with LDM for $48 \mathrm{~h}$ at the indicated concentrations and then harvested and labeled with a combination of FITC-Annexin V and PI and followed by flow cytometric analysis. Control (1.70\%); $0.1 \mathrm{nmol} / \mathrm{L}$ LDM (14.66\%); 0.5 nmol/L LDM (18.36\%); 1 nmol/L LDM (43.65\%); 2 nmol/L LDM (82.88\%).

Activation of JNK/caspase in LDM-induced apoptosis in SP2/0 cells

To determine whether LDM-induced cytotoxicity is mediated via the activation of caspase and/or PARP, SP2/0 cells were treated with LDM at various concentrations for $48 \mathrm{~h}$ or with $0.5 \mathrm{nmol} / \mathrm{L} \mathrm{LDM}$ for different time intervals. LDM induced caspase-3/7 and PARP cleavage in a dose- and timedependent manner (Figure 5A). Studies have shown that JNK activation plays an important role in apoptosis induced by some antitumor agents ${ }^{[20-24]}$. We next examined whether LDM induces phosphorylation of JNK during cell apoptosis. SP2/0 cells were treated with LDM at various concentrations for $48 \mathrm{~h}$ or with $0.5 \mathrm{nmol} / \mathrm{L}$ LDM for different time intervals. Our study showed that LDM strongly induced phosphorylation of JNK in SP2/ 0 cells in a dose- and time-dependent manner (Figure 5B). To determine the role of JNK in mediating LDMinduced cytotoxicity, SP2/0 cells were treated with LDM at different concentrations in the presence or absence of the JNK inhibitor SP600125. In the absence of LDM, the inhibition of JNK alone did not significantly alter cell growth in SP2/0 cells,
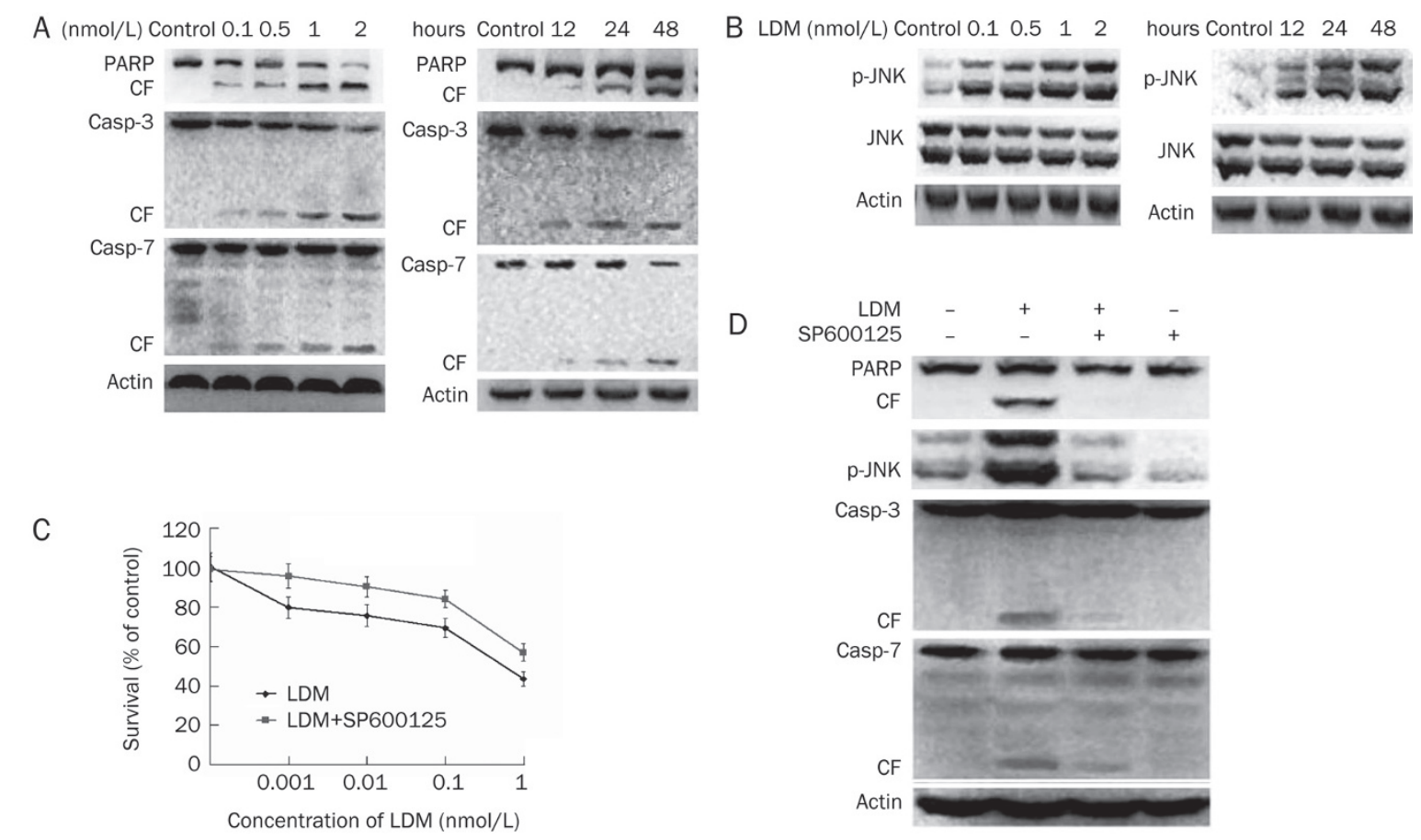

Figure 5. Effects of the activation of JNK on LDM-induced apoptosis. (A) Cells were cultured with LDM at different concentrations for $48 \mathrm{~h}$ and then lysed and subjected to Western blotting using anti-caspase-3, anti-caspase-7 and anti-PARP, and anti-Actin antibodies. One representative of three independent experiments is shown. (B) Cells were cultured with LDM $(0.5 \mathrm{nmol} / \mathrm{L})$ for the indicated periods and then were lysed and subjected to Western blotting using anti-p-JNK, anti-JNK, and anti-Actin antibodies. One representative of three independent experiments is shown. (C) Cells were cultured for $48 \mathrm{~h}$ with control media, or with $0.001 \mathrm{nmol} / \mathrm{L}, 0.01 \mathrm{nmol} / \mathrm{L}, 0.1 \mathrm{nmol} / \mathrm{L}$, and $1 \mathrm{nmol} / \mathrm{L} \mathrm{LDM}$, respectively, in the presence or absence of SP600125 $(10 \mu \mathrm{mol} / \mathrm{L})$ and determined by MTS Assay. Data represent the means \pm SD of three independent experiments. (D) Cells were cultured with LDM $(0.5 \mathrm{nmol} / \mathrm{L})$ for $48 \mathrm{~h}$ in the presence or absence of SP600125 $(10 \mu \mathrm{mol} / \mathrm{L})$. Cells were then lysed and subjected to Western blotting using antip-JNK, anti-PARP, anti-caspase-3, anti-caspase-7, and anti-Actin antibodies. One representative of three independent experiments is shown. Casp, caspase; $\mathrm{CF}$, cleaved fragment. 
whereas SP600125 significantly reduced LDM-induced cytotoxicity (Figure 5C). Consistent with the reduction of LDMinduced cytotoxicity, the phosphorylation of JNK and cleavage of caspase-3/7 and PARP triggered by LDM were blocked by SP600125 (Figure 5D), confirming that the activation of JNK and cleavage of caspase-3/7 and PARP are associated with LDM-induced apoptosis. These results suggest that JNK plays a role, at least in part, in SP2/0 cell apoptosis triggered by LDM.

\section{Inhibition of tumor growth of the SP2/0 myeloma}

We next sought to determine whether LDM inhibits tumor growth of the SP2/0 myeloma in BALB/c mice. SP2/0 cells $\left(1 \times 10^{6}\right)$ resuspended in $200 \mu \mathrm{L}$ PBS were injected subcutaneously into the right axillary region of BALB/c mice. Treatment was started on day +1 after cell inoculation. LDM was given iv at doses of $0.06 \mathrm{mg} / \mathrm{kg}, 0.04 \mathrm{mg} / \mathrm{kg}$, or $0.02 \mathrm{mg} / \mathrm{kg}$ through the caudal vein. On day +8 , LDM was given for a second time. Control mice were given PBS vehicle only. Serial caliper measurements of perpendicular diameters were taken every 3 days to calculate tumor volume. Administration of LDM significantly reduced SP2/0 myeloma tumor growth, compared with control animals treated with PBS vehicle only. Comparisons of tumor volumes on day 20 after tumor implantation showed statistically significant differences across the groups and revealed significantly lower tumor volumes in the LDM-treated groups versus the control group. Treatment with LDM at the dose of $0.06 \mathrm{mg} / \mathrm{kg}, 0.04 \mathrm{mg} / \mathrm{kg}$, and $0.02 \mathrm{mg} / \mathrm{kg}$ inhibited the growth of SP2/0 myeloma by $92.1 \%$, $74.6 \%$, and $35.9 \%$, respectively. On day 35 after tumor implantation, BALB/c mice were sacrificed by cervical dislocation, and tumors were carefully taken and weighed. Comparison of tumor weights also showed significantly lower tumor weights in the LDM-treated groups versus the control group. There was no significant body weight loss in the treated groups compared with the control group. All animals survived the duration of the experiment (Figure 6).

\section{Discussion}

Despite the emergence of new treatments in recent years, multiple myeloma is still an incurable disease. It is characterized by the presence of malignant plasma cells predominantly located in the bone marrow. Existing treatment mainly attempts to reduce the malignant cell masses and to overcome the disease-related complications. Although initial chemotherapeutic treatment can be successful, drug resistance often develops during disease progression, requiring the use of alternative drugs. Over the past several years, significant insight into the dysregulation of various signal transduction pathways of myeloma cells has led to the development of new agents.

LDM is currently being evaluated in clinical trials as a potential anticancer agent in China. Its mode of action is complex. The vast majority of studies aimed at elucidating the mode of action of LDM have been performed in solid tumor cells. No studies have examined the effect of this drug on myeloma

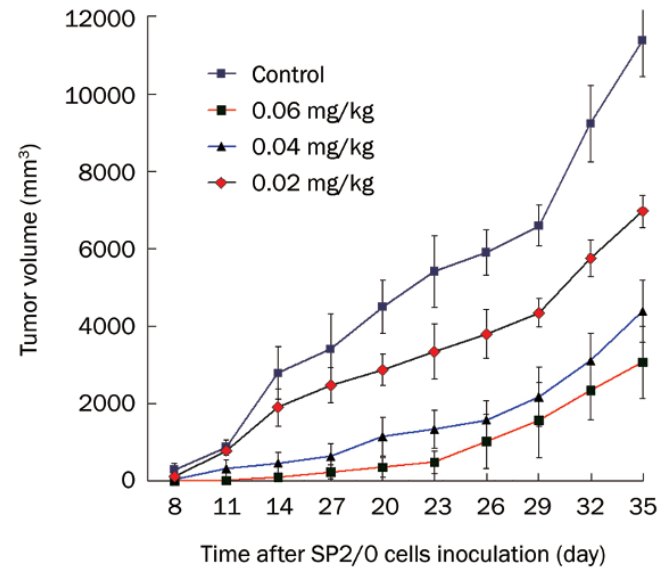

Figure 6. Effects of LDM on the growth of SP2/0 myeloma in BALB/c mice. SP2/0 cells were subcutaneously inoculated into the right axillary region of BALB/c mice. Twenty-four hours after cell inoculation, the mice were given PBS, $0.02 \mathrm{mg} / \mathrm{kg}$ LDM, $0.04 \mathrm{mg} / \mathrm{kg}$ LDM, and $0.06 \mathrm{mg} / \mathrm{kg}$ LDM, respectively, by intravenous injection. Second injection was given seven days later. Tumor volume was monitored every 3 days for 5 weeks.

cells. In the present study, LDM exhibited extremely potent cytotoxicity in SP2/ 0 cells. The $\mathrm{IC}_{50}$ value of LDM for SP2/0 was $0.56 \mathrm{nmol} / \mathrm{L}$, much lower than those of ADM, 5-FU, VCR, and DEX. The increase in apoptosis rate was observed after incubation of SP2/0, U266, and SKO-007 cells with LDM ranging from 0.1 to $2 \mathrm{nmol} / \mathrm{L}$, and the cells displayed typical apoptotic features, including cellular morphological changes and chromatin condensation. Moreover, LDM-induced cell cycle arrest at the $\mathrm{G}_{2} / \mathrm{M}$-phase. The LDM-induced apoptosis could be related to certain molecular changes involving cleavage of caspase- $3 / 7$ and PARP.

Taken together, these results strongly suggest that LDM triggers caspase-dependent apoptosis in SP2/0 cells. As reported, JNK plays a crucial role in apoptosis induced by novel therapeutic agents, including bortezomib, perifosine, and lysophosphatidic acid acyltransferase- $\beta$ inhibitors ${ }^{[20-23]}$. Moreover, a sustained activation of JNK plays a critical role in arsenic trioxide-induced cell apoptosis in multiple myeloma cell lines ${ }^{[24]}$. It has been shown that activation of the JNK pathway is a common phenomenon in stress-induced apoptosis in response to stress stimuli, such as UV light, heat shock, and ionizing radiation ${ }^{[25]}$. In addition, the JNK pathway is activated by intracellular stresses, such as inhibition of protein synthesis, DNA damage, and treatment with anticancer agents ${ }^{[25-28]}$. The role of activated JNK in LDM-induced apoptosis, however, remains to be elucidated. In the present study, we examined the LDM-induced phosphorylation of JNK during apoptosis of myeloma cells and the correlation between LDM-induced apoptosis and the degree of JNK activation.

Analysis of cells treated with various concentrations of LDM at different time points showed that sustained activation of JNK was needed for the LDM-induced apoptosis of SP2/0 cells. As expected, the JNK inhibitor SP600125 blocks the cleavage of caspase-3/7 and PARP as well as cytotoxicity. 
Taken together, these results indicate that JNK plays an important role in the LDM-induced apoptosis of SP2/0 cells. The JNK-stimulated apoptosis might involve Bax and Bak, which are essential for JNK-regulated apoptosis.

The murine 5T33MM myeloma model and the murine SP2/0 myeloma model are used in testing the effects of antitumor agents in vivo ${ }^{[29,30]}$. The murine 5T33MM myeloma model is used frequently. In our study, LDM is well tolerated and very effective in vivo in the murine SP2/0 myeloma model, evidenced by significant inhibition of tumor growth in mice treated with $0.06 \mathrm{mg} / \mathrm{kg}, 0.04 \mathrm{mg} / \mathrm{kg}$, or $0.02 \mathrm{mg} / \mathrm{kg}$ LDM once a week for two weeks administered via the caudal vein. These results, coupled with the effective doses well-tolerated in animals, provide the framework for further studies of LDM treatment for human multiple myeloma.

\section{Acknowledgements}

This study was supported by the National High Technology Research and Development 863 Program of China (No 2004AA2Z3950) and the Key Basic Research Development 973 Program Foundation of China (№ 2004CB518706).

\section{Author contribution}

Yong-zhan ZHEN designed and performed research and wrote the paper; Ya-jun LIN performed research; Yi LI performed research; Yong-su ZHEN designed research.

\section{Abbreviations}

LDM, lidamycin; VCR, vincristine; 5-FU, 5-fluorouracil; DEX, dexamethasone; ADM, adriamycin; PI, propidium iodide; JNK, c-Jun N-terminal kinase; DMSO, dimethyl sulfoxide; FITC, fluorescein isothiocyanate; PARP, poly (ADP-ribose) polymerase; CF, cleaved fragment; Casp, caspase; MM, multiple myeloma; MTS, 3-[4,5-dimethylthiazol-2-yl]5-[3carboxymethoxyphenyl]-2-[4-sulfophenyl]2H-tetrazolium inner salt; PMS, phenazine methosulfate.

\section{References}

1 Gregory WM, Richards MA, Malpas JS. Combination chemotherapy versus melphalan and prednisolone in the treatment of multiple myeloma: an overview of published trials. J Clin Oncol 1992; 10: 334-42.

2 Chiusolo P, Sica S, Piccirillo N, Giordano G, Laurenti L, La Barbera EO, et al. Molecular and clinical follow-up after stem cell transplantation for multiple myeloma. Ann Hematol 2001; 80: 90-5.

3 Iguchi T, Yachide-Noguchi T, Hashimoto Y, Nakazato S, Sagawa M, Ikeda $\mathrm{Y}$, et al. Novel tubulin-polymerization inhibitor derived from thalidomide directly induces apoptosis in human multiple myeloma cells: possible anti-myeloma mechanism of thalidomide. Int J Mol Med 2008; 21: 163-8.

4 Chauhan D, Hideshima T, Anderson KC. Targeting proteasomes as therapy in multiple myeloma. Adv Exp Med Biol 2008; 615: 251-60.

5 Pineda-Roman M, Zangari M, van Rhee F, Anaissie E, Szymonifka J, Hoering A, et al. VTD combination therapy with bortezomibthalidomide-dexamethasone is highly effective in advanced and refractory multiple myeloma. Leukemia 2008; 22: 1419-27.

6 Potter M, Fahey JL. Studies on eight transplantable plasma-cell neoplasms of mice. J Natl Cancer Inst 1960; 24: 1153-65.

7 Foster L, Catzel D, Atwa S, Zarka M, Mahler SM. Increase in synthesis of human monoclonal antibodies by transfected Sp2/0 myeloma mouse cell line under conditions of microgravity. Biotechnol Lett 2003; 25: 1271-4.

8 Hu JL, Xue YC, Xie MY, Zhang R, Otani T, Minami Y, et al. A new macromolecular antitumor antibiotic, C-1027. I. Discovery, taxonomy of producing organism, fermentation and biological activity. J Antibiot 1988; 41: 1575-9.

9 Xu YJ, Zhen YS, Goldberg IH. C1027 chromophore, a potent new enediyne antitumor antibiotic, induces sequencespecific doublestrand DNA cleavage. Biochemistry 1994; 33: 5947-54.

10 Huang YH, Shang BY, Zhen YS. Antitumor efficacy of lidamycin on hepatoma and active moiety of its molecule. World J Gastroenterol 2005; 11: 3980-4.

11 Chen J, Ouyang ZG, Zhang SH, Zhen YS. Down-regulation of the nuclear factor-kappaB by lidamycin in association with inducing apoptosis in human pancreatic cancer cells and inhibiting xenograft growth. Oncol Rep 2007; 17: 1445-51.

12 Tanaka T, Fukuda-Ishisaka S, Hirama M, Otani T. Solution structures of $\mathrm{C}-1027$ apoprotein and its complex with the aromatized chromophore. J Mol Biol 2001; 309: 267-83.

13 Shao RG, Zhen YS. Relationship between the molecular composition of $\mathrm{C} 1027$, a new macromolecular antibiotic with enediyne chromophore, and its antitumor activity. Acta Pharm Sin 1995; 30: 336-42.

14 He QY, Liang YY, Wang DS, Li DD. Characteristics of mitotic cell death induced by enediyne antibiotic lidamycin in human epithelial tumor cells. Int J Oncol 2002; 20: 261-6.

15 Chen J, Wu SY, Ou-Yang ZG, Zhen YS. Synergy of gemcitabine and lidamycin associated with NF-kappaB downregulation in pancreatic carcinoma cells. Acta Pharmacol Sin 2008; 29: 614-9.

16 Kennedy DR, Beerman TA. The radiomimetic enediyne C-1027 induces unusual DNA damage responses to double-strand breaks. Biochemistry 2006; 45: 3747-54.

17 Liu X, Bian C, Ren K, Jin H, Li B, Shao RG. Lidamycin induces marked G2 cell cycle arrest in human colon carcinoma HT-29 cells through activation of p38 MAPK pathway. Oncol Rep 2007; 17: 597-603.

18 McHugh MM, Gawron LS, Matsui S, Beerman TA. The antitumor enediyne C-1027 alters cell cycle progression and induces chromosomal aberrations and telomere dysfunction. Cancer Res 2005; 65: 5344-51.

19 Iwamoto T, Hiraku Y, Kojima M, Kawanishi S. Amplification of C1027induced DNA cleavage and apoptosis by a quinacrine-netropsin hybrid molecule in tumor cell lines. Arch Biochem Biophys 2005; 434: 232-40.

20 Hideshima T, Mitsiades C, Akiyama M, Hayashi T, Chauhan D, Richardson $\mathrm{P}$, et al. Molecular mechanisms mediating antimyeloma activity of proteasome inhibitor PS-341. Blood 2003; 101: 1530-4.

21 Hideshima T, Catley L, Yasui H, Ishitsuka K, Raje N, Mitsiades C, et al. Perifosine, an oral bioactive novel alkylphospholipid, inhibits Akt and induces in vitro and in vivo cytotoxicity in human multiple myeloma cells. Blood 2006; 107: 4053-62.

22 Hideshima T, Chauhan D, Hayashi T, Podar K, Akiyama M, Mitsiades $C$, et al. Antitumor activity of lysophosphatidic acid acyltransferase- $\beta$ inhibitors, a novel class of agents, in multiple myeloma. Cancer Res 2003; 63: 8428-36.

23 Rahmani M, Reese E, Dai Y, Bauer C, Payne SG, Dent P, et al. Coadministration of histone deacetylase inhibitors and perifosine synergistically induces apoptosis in human leukemia cells through Akt and ERK1/2 inactivation and the generation of ceramide and reactive oxygen species. Cancer Res 2005; 65: 2422-32. 
24 Kajiguchi T, Yamamoto K, lida S, Ueda R, Emi N, Naoe T. Sustained activation of c-jun-N-terminal kinase plays a critical role in arsenic trioxide-induced cell apoptosis in multiple myeloma cell lines. Cancer Sci 2006; 97: 540-5.

25 Shtil AA, Mandlekar S, Yu R, Walter RJ, Hagen K, Tan TH, et al. Differential regulation of mitogen-activated protein kinases by microtubule-binding agents in human breast cancer cells. Oncogene 1999; 18: 377-84.

26 Kyriakis JM, Avruch J. Mammalianmitogen-activated protein kinase signal transduction pathways activated by stress and inflammation. Physiol Rev 2001; 81: 807-69.

27 Wang TH, Wang HS, Ichijo H, Giannakakou P, Foster JS, Fojo T, et al. Microtubule-interfering agents activate c-Jun $\mathrm{N}$-terminal kinase/ stress-activated protein kinase through both Ras and apoptosis signal-regulating kinase pathway. J Biol Chem 1998; 273: 4928-36.

28 Stone AA, Chambers TC. Microtubule inhibitors elicit differential effects on MAP kinase (JNK, ERK, and p38) signaling pathways in human KB-3 carcinoma cells. Exp Cell Res 2000; 254: 110-9.

29 Caers J, Menu E, De Raeve H, Lepage D, Van Valckenborgh E, Van Camp B, et al. Antitumour and antiangiogenic effects of Aplidin in the 5TMM syngeneic models of multiple myeloma. Br J Cancer 2008; 98 : 1966-74.

30 Dou J, Chu L, Zhao F, Tang Q, Zhang A, Zhang L, et al. Study of immunotherapy of murine myeloma by an IL-21-based tumor vaccine in BALB/C mice. Cancer Biol Ther 2007; 6: 1871-9. 